\title{
A Model-Based Analysis of Metal Fate in the Thames Estuary
}

\author{
Valentina Premier ${ }^{1,2}$ (1) - Anderson Abel de Souza Machado $2,3,4 \cdot$ Steve Mitchell ${ }^{5}$. Christiane Zarfl ${ }^{6}$ Kate Spencer $^{4}$. \\ Marco Toffolon ${ }^{1}$
}

Received: 28 November 2018 / Revised: 4 March 2019 / Accepted: 5 March 2019 / Published online: 22 March 2019

(c) Coastal and Estuarine Research Federation 2019

\begin{abstract}
The Thames Estuary (UK) is an industrialized, macrotidal ecosystem characterized by a long history of metal pollution. Nevertheless, a holistic understanding of the metal fate is still missing. This study aims at identifying the main environmental mechanisms affecting metal behaviour in the Thames Estuary using copper and zinc as representative examples. A suite of multivariate statistical analyses performed on data from long-term monitoring of metal distribution in the estuary indicated that total metal concentrations are primarily correlated with suspended solids, being thus indirectly influenced by the interaction between freshwater discharge and the tide. These data were used to set up a three-dimensional hydrodynamic and water quality model to simulate the transport of sediments and metals within the estuary. Model results ratify that high metal concentrations might occur in the central part of the estuary as consequence of fine sediment resuspension. Such an effect of the hydrodynamics is highlighted by the differences between months characterized by low or high river discharge as well as neap or spring tide. We discuss the physical mechanisms of such transport processes and their direct implication for the management of sediment and metal contamination in estuarine areas especially in terms of long-term analysis. Developing a model able to assess future trends helps in planning the correct strategies for recovery and maintenance. Further research is needed to improve the accuracy of models of this kind as well as to investigate the potential effects of climate change for this and other similar systems.
\end{abstract}

Keywords Numerical modelling $\cdot$ Estuarine hydrodynamics $\cdot$ Salinity $\cdot$ Metals $\cdot$ Suspended sediments

\section{Introduction}

Estuaries are coastal water bodies where freshwater from continental sources is diluted by seawater from the marine environment. Thus, estuaries present hydrodynamics and biogeochemistry with both freshwater and marine characteristics (Hobbie 2000), a condition that contributes to high biodiversity and to the provision of diverse ecosystem services. The abundance of such natural resources and the strategic position in terms of transport and food supply have turned estuaries into often densely populated and exploited

Communicated by Wen-Xiong Wang

Electronic supplementary material The online version of this article (https://doi.org/10.1007/s12237-019-00544-y) contains supplementary material, which is available to authorized users.

Valentina Premier

valentina.premier@unitn.it

Extended author information available on the last page of the article. areas, which have in many cases led to severe pollution conditions (Savenije 2012; Lotze et al. 2006).

The Thames Estuary, as the recipient of waters from London, UK, is representative of a heavily engineered and industrialized macrotidal system. Its status affords special significance for researchers and managers due to its historical levels of pollution and relatively low residence time for an estuary of its size. Its urban and estuarine reaches were so severely polluted between the early 1960s and late 1970s that it was called an 'open sewer' (Attrill et al. 1996). Historical sewage sludge dumping into the estuary together with other urban and industrial activities led to a legacy of metal accumulation in the sediments (Vane et al. 2015). In turn, such interaction with sediments is influencing the environmental risk and the residence time of pollutants (Hobbie 2000; Bianchi 2006). Metals attached to particles can be mobilized to the aqueous fraction, in which toxic effects might be noticed at trace concentrations (in the range of $\mu \mathrm{g} \mathrm{L}^{-1}$ ) (Förstner and Wittmann 2012). In fact, a recent study suggested that dissolved, adsorbed and colloidal metal in the tidal sediments from the Thames Estuary might 
undergo high remobilization to the water column, where its fate will be greatly impacted by the hydrodynamics (de Souza Machado et al. 2018).

Copper and zinc, along with many other transition metals, are often mentioned as toxic and potentially bioavailable metals (Förstner and Wittmann 2012; Paquin 2003). In the Thames Estuary, these two metals consistently exceeded the environmental quality standards (EQS) values of respectively 5 and $40 \mu \mathrm{g} / \mathrm{L}$ (Pope and Langston 2011). Since the 1980s, most water quality parameters have consistently improved due to stricter regulations, and some studies suggest that metal concentration is decreasing (Langston et al. 2003; Murray et al. 2011). Notwithstanding, the Thames Estuary was without any comprehensive studies on metal behaviour in water or sediment until the 1990s (Attrill and Thomes 1995) and it still lacks holistic studies on the fate of metal pollution.

Therefore, a better empirical and mechanistic understanding of the fate of metals in the Thames Estuary is essential to develop a more effective management. In particular, the combination of hydrodynamic and transport processes on metal behaviour needs to be investigated in detail, in order to predict variability of metals throughout the estuary especially from a long-term view. The set-up of a model represents a precious help in understanding the main natural dynamics, especially when continuous measurements are missing. For this reason, modelling studies were carried out for systems with similar characteristics in terms of level of industrialization and tidal range such as the Scheldt Estuary (The Netherlands) (e.g. Gourgue et al. 2013; De Brye et al. 2010; Cai et al. 2012), the Seine estuary (France) (Thouvenin et al. 2007, e.g. Chauchat et al. 2009), the Ems (de Jonge et al. 2014) or the Derwent estuary (Tasmania) (e.g. Wild-Allen et al. 2013; Skerratt et al. 2013), though in all cases, the focus on metals and the link with sediments still need improvement in terms of the models used. In fact, several authors point to the need to holistically address metal pollution in estuaries (Bianchi 2006; de Souza Machado et al. 2016).

We present here a list of the existing studies on the Thames Estuary. Most of them considered a specific part of the estuary and a limited observation period. For instance, Baugh and Littlewood (2005) presented a three-dimensional (3D) model for the transport of cohesive sediments, which was later applied by Baugh and Manning (2007) for the Lower Thames Estuary. Analogous studies were performed also by Spearman et al. (2011) examining the effects of sand and mud interactions with a one-dimensional (1D) vertical model for the Outer Thames Estuary. A 1D hydrodynamic and water quality model was set up by Murray et al. (2011) to investigate copper contamination in the estuary. Knaapen and Kelly (2012) included a lag effect for the response of the sediment concentration profile to flow variations and tested it for the Outer Thames Estuary. A morphological model was also set up by Rossington and Spearman (2009) in order to predict the effects of sea level rise on the long-term morphological evolution. Although these modelling studies have no doubt improved our knowledge of the mechanisms that underpin the transport of solutes and sediments in the estuary, there are still significant gaps in our understanding, for this and other estuarine systems, on the determining effects of tidal and freshwater forcing on the distribution of fine sediments and the related transport of metals. Furthermore, the complexity of the system is enhanced since metals behave as non-conservative constituents, i.e. they are subjected to a net loss or gain in concentration across the salinity gradient, due to different biogeochemical processes (Boyle et al. 1974; Bianchi 2006; de Souza Machado et al. 2016). Only by understanding the response of the system to long-term changes can we begin to make progress in modelling these processes, enabling managers and other stakeholders to assess the effects of sea level rise or other interventions.

This study integrates estuarine hydrodynamics, sediment transport and remobilization as well as fate of metals in a numerical model that represents the whole estuary. The model was designed to realistically represent the complex non-linear dependence of metal concentrations on different estuarine properties (e.g. salinity) as a result of the interaction between freshwater discharge and tide. An exploratory analysis of the available data on metal distribution was performed in order to identify the most important estuarine characteristics for the interactions between the flow field and the transport of sediments and metals. Then, a state-of-the-art 3D hydrodynamic and water quality model was set exploiting the Delft3D suite (Lesser et al. 2004). An entire year (2006) was modelled, in order to assess the ability of this model to compute metal concentrations during dry and rainy periods. The accuracy, applicability and implications of the model are discussed in terms of a potential tool for the future management of metal pollution in estuaries.

\section{Materials and Methods}

\section{Study Area}

The study area is the estuary of the River Thames, which discharges into the North Sea near London (UK). The Thames rises in the Cotswold Hills and runs for a length of about $350 \mathrm{~km}$. Including its major tributary, the River Medway, the catchment covers an area of ca. $15,000 \mathrm{~km}^{2}$ (Fig. 1). From London Bridge (assumed as the origin of the longitudinal coordinate directed seaward), the estuary becomes funnel-shaped, with the width increasing from 


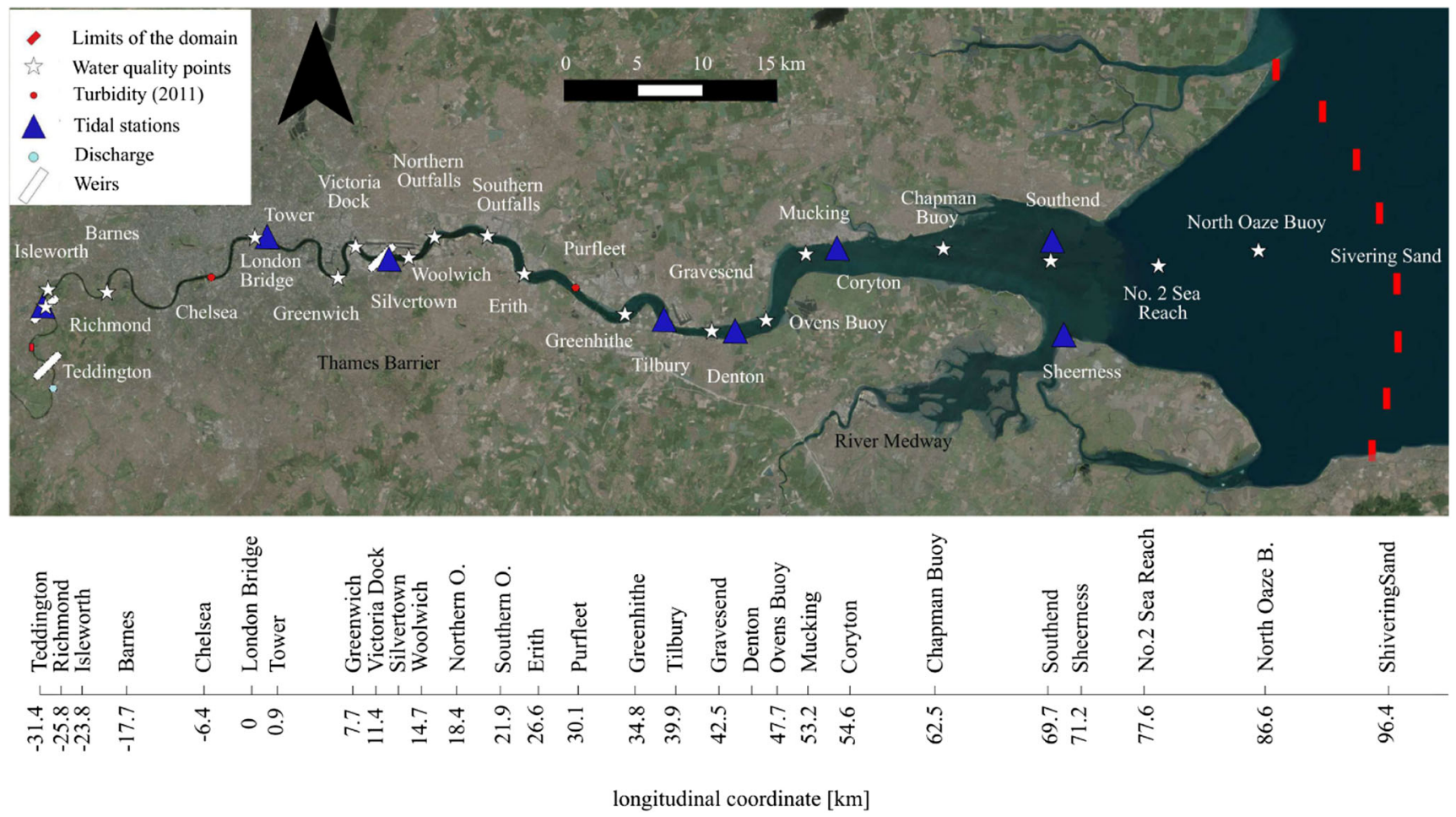

Fig. 1 The Thames Estuary with the boundaries assumed for the current study, the position of the weirs and the observation points

$265 \mathrm{~m}$ to $8 \mathrm{~km}$ at the estuary mouth (close to Sheerness). The mean channel depth at the mean tidal water level increases from $2 \mathrm{~m}$ at Teddington Lock to $7 \mathrm{~m}$ upstream of London Bridge and $10 \mathrm{~m}$ downstream of London Bridge, up to values of $20 \mathrm{~m}$ in the deepest channels (Mikhailova 2011; Mikhailov and Mikhailova 2012). All these channels are subject to maintenance dredging. Along the Thames Estuary, three main weirs are present: Teddington and Richmond Locks in the upstream part and the Thames Barrier downstream of London to defend the city from flooding due to tidal and storm surge effects.

The Thames Estuary is macrotidal (tidal range larger than $4 \mathrm{~m}$ ). The mean values of spring and neap tides at the estuary mouth are 5.3 and $3.3 \mathrm{~m}$, respectively. The tidal wave is amplified up to London Bridge due to the prevalent convergence of the banks compared with bottom friction (e.g. Jay 1991; Toffolon et al. 2006; Cai et al. 2012). From this point landwards, the tidal range rapidly drops because the convergence almost disappears (Mikhailov and Mikhailova 2012). The mean discharge at Teddington dam is about $80 \mathrm{~m}^{3} / \mathrm{s}$ but during floods can reach $600-700$ $\mathrm{m}^{3} / \mathrm{s}$ (Mikhailova 2011). Tide effects are dominant over freshwater flow in the whole estuary, resulting in an intense vertical mixing and, hence, in a well-mixed estuary (Preddy 1954). The estuary is influenced by the effects of tidal asymmetry, the distortion of the tidal wave that makes the flood period unequal in the duration to the ebb period, causing the flood currents to be faster than the ebb currents, at least during periods of low freshwater flow. If the period of water level rise is shorter than the period of water level fall, the maximum flood velocity exceeds ebb velocity and the tide is called flood-dominant. In the opposite case, it is called ebb-dominant. The Thames is flood-dominant especially in the upstream part, whereas between Sheerness and Gravesend, maximum ebb current velocities are in excess of the flood. The switch of tidal dominance coincides with the narrowing of the channel (Thorn and Burt 1978; Wang et al. 1999).

The Thames Estuary can be divided into three main sedimentation zones. The reach from Teddington to approximately Tower Bridge is characterized by land-derived sediment, low suspended load and reduced deposition on the bed and banks. From Woolwich to Gravesend, suspended load and sedimentation are high, and bed sediments are composed of clay to fine sand. The estuarine turbidity maximum (ETM) usually occurs in the so-called Mud Reaches between Woolwich and Erith (18-24 km downstream of the London Bridge) and the Gravesend Reach (43-44 km from the London Bridge). The third zone, from Gravesend to the Sea Reach, is sandy and dominated by bed-load transport (Prentice 1972). Mitchell et al. (2012) also showed the highly mobile characteristics of the ETM in response to tidal and freshwater forcing, with values of total suspended solids (TSS) varying from 0 to $600 \mathrm{mg} / \mathrm{L}$ upstream of London Bridge in response to reduction in freshwater flow from 400 to $30 \mathrm{~m}^{3} / \mathrm{s}$ from winter to summer. 
The importance of understanding the variations in sediment budget over several decades is crucial (Baugh et al. 2013) because changes in dredging regime and other engineering schemes may effectively constrain different 'pools' of sediment in different parts of the estuary, to a greater or lesser extent. Moreover, the highest concentrations of metals in water coincide with high turbidity in the middle region. There are also many sewage treatment water effluents in this area and the resuspension of sediments is reinforced by tidal and wind influence (Pope and Langston 2011). Attrill and Thomes (1995) showed a gradual decrease in the metal concentrations towards the North Sea and the absence of significant peaks in proximity of Teddington, suggesting that both the input from the sea and the river do not represent important sources.

\section{Data Sources and Use}

A major effort was made to obtain comprehensive information about metal behaviour in the whole estuary, which resulted in compiling several databases from various sources, as acknowledged below.
The exploratory analysis was based on the data provided by the Environment Agency of England and Wales (hereafter 'Environment Agency', see https://www. environment-agency.gov.uk) containing several water quality parameters, including salinity, TSS, organic matter, water physico-chemistry and metal concentrations for the period from 2002 to 2011 . The water quality stations are reported in Table 1. These data were available with certain irregular temporal resolution, e.g. salinity data were missing for 2002 and metal concentrations were not complete for the years 2010 and 2011. These point samples were obtained from boat-based surveys, which sometimes implied a potential lack of consistency regarding the tidal state at the time. Consequentially, these values must be treated with some caution where significant variation within tidal cycles can be expected. All salinity values are quoted without units and according to the practical salinity scale.

Water quality parameters were available at all monitoring points represented in Fig. 1 except for Purfleet. Metals were available as 'total' and 'dissolved', but the dissolved fraction presented some inconsistencies with some values greater than the total concentration. Therefore, only the

Table 1 Main features of the boundary conditions (year 2006) and mean values of the measured quantities at the observation points

\begin{tabular}{|c|c|c|c|c|c|}
\hline & Quantity & Unit & Min & Mean & Max \\
\hline River Thames & Discharge & $\left(\mathrm{m}^{3} \mathrm{~s}^{-1}\right)$ & 3.11 & 40.74 & 249 \\
\hline River Medway & Discharge & $\left(\mathrm{m}^{3} \mathrm{~s}^{-1}\right)$ & 1.56 & 7.13 & 87.97 \\
\hline \multirow[t]{2}{*}{ Shivering Sands } & Water level & $(\mathrm{m})$ & -2.875 & 0.0005 & 2.975 \\
\hline & $\begin{array}{l}\text { Distance * } \\
(\mathrm{km})\end{array}$ & $\begin{array}{l}\text { Salinity } \\
(-)\end{array}$ & $\begin{array}{l}\text { TSS } \\
(\mathrm{mg} / \mathrm{L})\end{array}$ & $\begin{array}{l}\text { Total } \mathrm{Cu} \\
(\mu \mathrm{g} / \mathrm{L})\end{array}$ & $\begin{array}{l}\text { Total Zn } \\
(\mu \mathrm{g} / \mathrm{L})\end{array}$ \\
\hline Richmond & -25.8 & 0.36 & 23.7 & 4.02 & 18.60 \\
\hline Isleworth & -23.8 & 0.36 & 29.8 & 4.34 & 20.40 \\
\hline Barnes & -17.7 & 0.45 & 54.7 & 7.58 & 22.87 \\
\hline London Bridge & 0 & 1.37 & 82.1 & 8.68 & 28.50 \\
\hline Greenwich & 7.7 & 2.73 & 75.5 & 8.61 & 27.77 \\
\hline Victoria Dock & 11.4 & 3.80 & 74.1 & 8.83 & 28.33 \\
\hline Woolwich & 14.7 & 4.80 & 76.3 & 7.46 & 26.14 \\
\hline Northern outfalls & 18.4 & 6.00 & 68.9 & 7.12 & 27.02 \\
\hline Southern outfalls & 21.9 & 7.93 & 65.6 & 8.06 & 28.82 \\
\hline Erith & 26.6 & 9.59 & 66.4 & 7.65 & 28.33 \\
\hline Greenhithe & 34.8 & 13.56 & 95.4 & 9.25 & 31.04 \\
\hline Gravesend & 42.5 & 17.29 & 174.1 & 9.11 & 29.53 \\
\hline Ovens Buoy & 47.7 & 19.13 & 113.1 & 7.86 & 24.12 \\
\hline Mucking & 53.2 & 20.85 & 73.6 & 7.86 & 23.19 \\
\hline Chapman Buoy & 62.5 & 25.66 & 39.9 & 9.30 & 17.49 \\
\hline Southend & 69.7 & 28.50 & 25.7 & 6.14 & 10.25 \\
\hline No. 2 Sea Reach & 77.6 & 30.45 & 19.8 & 6.89 & 7.80 \\
\hline North Oaze Buoy & 86.6 & 31.87 & 25.2 & 7.76 & 5.45 \\
\hline
\end{tabular}

* Distance is measured from London Bridge, assumed the head of the estuary, in the seaward direction 
total concentration was considered in the analysis and the division into dissolved and adsorbed fractions was taken into account in the numerical model considering an empirically determined partition coefficient for each metal. Most of the complete data spanned a period of seven years (2003-2009), which was considered representative for the exploratory analysis. Additionally, as water quality data were occasionally missing, monthly averages were calculated for all parameters. Regression analyses were performed for copper $(\mathrm{Cu})$ and zinc $(\mathrm{Zn})$ : as these two metals are problematic contaminants in the Thames estuary (Murray et al. 2011; Pope and Langston 2011), high-frequency monitoring data were available and they are representative of ubiquitous anthropogenic metals in estuarine environments.

In addition to the above described data used for the empirical analysis, other datasets were used for the computation of the numerical model. The geomorphology and bathymetry data were provided by the Port of London Authority (reference system WGS84/UTM31N and Ordnance Datum Newlyn (ODN) for the vertical datum). Freshwater discharge (Q) of the River Thames measured immediately upstream of Teddington and discharge of River Medway were available from 1883 to 2012 with a daily resolution and were provided by the Environment Agency.

The water level (WL) was measured at a number of different observation points throughout the estuary (Fig. 1) every $30 \mathrm{~min}$ by the Environment Agency. The seaward boundary condition was imposed at Shivering Sands and water levels were obtained from Delft Dashboard, making use of the International Hydrographic Organization (IHO) tide station (Intergovernmental Oceanographic Commission 2003), because of the absence of available gauging stations. Since the water level time series were derived with astronomical tidal constituents, the effects of storm surges are not considered in the numerical model. Nevertheless, a good correlation coefficient was obtained for measured and computed water levels in Sheerness ( 0.97 for the whole series or 0.99 excluding storm surge events; see Figure S3 in the Supplementary Material). In order to recognize the effects of the tidal forcing, we separated periods of spring and neap tides. The division was based on the water level at Sheerness. Days with a tidal range greater than the median of the time series $(4 \mathrm{~m})$ were classified as spring tide and lower values as neap tide.

The numerical model was additionally tested at higher temporal resolution in two periods (February and August 2011) exploiting fixed-point continuous measurements of turbidity (Mitchell et al. 2012). An approximate linear relationship was suggested between turbidity and TSS (1 NTU:1 mg/L). These data were collected at Chelsea and Purfleet (red dots in Fig. 1) with probes located near the bank of the channel and attached to pontoons or floating jetties. They reflect the conditions about $1 \mathrm{~m}$ below the surface, thus representing lower than section-mean values especially when the velocities are low.

\section{Implementation of the Model}

A reach of the Thames Estuary was selected to study the fate of metals, with a total length of about $120 \mathrm{~km}$ and a total area of about $580 \mathrm{~km}^{2}$ (Fig. 1). The computational grid was composed of $913 \times 57$ horizontal cells with 6852 active grid elements per layer, and 15 vertical layers. For the vertical discretization, a $\sigma$-approach (i.e. stretched coordinates with the same number of layers from the free surface to the bottom) was adopted. The cell area varies upstream to downstream from 300 to $170,000 \mathrm{~m}^{2}$. The same grid was used for the hydrodynamic (Delft3D-FLOW) and water quality (Delft3D-WAQ) modules. Delft3D-FLOW solves the turbulence-averaged, shallow water equations derived from the Navier-Stokes equations for an incompressible fluid under the Boussinesq assumption. Transport processes are modelled by an advection-diffusion equation (Lesser et al. 2004). A time step of 0.2 min was used. Delft3D-WAQ solves an advection-diffusion-reaction equation making use of the hydrodynamic results of Delft3D-FLOW. Suspended solids, copper, and zinc were implemented in the present study. For the water quality model, a time step of 5 min was used.

A simplified approach was adopted to simulate the exchange of sediments with the bed in Delft3D-WAQ, namely the S1/S2 model, where two bed layers denoted with S1 and S2 are simulated separately from the water layers (Lesser et al. 2004). Within the S1/S2 framework, the two layers are modelled as 'inactive substances' subject only to conversion processes and not to mass transport. In this study, only the upper S1 layer was assumed as relevant, and the exchange with the deeper layer S2 was considered negligible for the investigated time scales. Sediments were modelled as suspended solids of the type 'inorganic matter' (IM), with particles size defined indirectly through the sedimentation velocity. The reader is referred to the Supplementary Material for more details.

Metals were modelled accounting for partitioning, i.e. the distinction of total concentrations into dissolved and particulate fractions. The two fractions behave differently, in particular the particulate fraction is subjected to the same processes as suspended solids (resuspension and sedimentation), while the dissolved part is directly affected by advection and diffusion processes (e.g. Benoit et al. 1994).

The upstream boundary of the computational domain was chosen immediately downstream of the estuarine tidal limit at Teddington Lock. A cross section located in the proximity of the Shivering Sands was adopted as the seaward 
downstream boundary, which included the nearshore area of the North Sea. The main statistics regarding discharge and water level used as boundary conditions are reported in Table 1 (see the Supplementary Material for more details). The weirs present in the estuary were not integrated in the model, possibly causing short-term inconsistencies between modelled and measured values in the landward areas. However, their exclusion from the model does not affect the main conclusions of the present study, which is focused on time scales longer than weir closing operations.

Measured values of salinity, total suspended solids (TSS) and total $\mathrm{Cu}$ and $\mathrm{Zn}$ (Table 1) were used as reference for setting the boundary conditions for the water quality model. For the River Medway, no detailed data were available, so the same boundary conditions of River Thames were imposed as representative for these freshwater bodies. Salinity was fixed as 0.35 for the freshwater inputs and 34 for the sea boundary (Weston et al. 2008; Sanders et al. 2001). TSS concentration was fixed at $25 \mathrm{mg} / \mathrm{L}$ for the rivers and $30 \mathrm{mg} / \mathrm{L}$ for the sea, given the average concentrations in the upstream and downstream sections reported in Table 1. Metal concentration was assumed $5 \mu \mathrm{g} / \mathrm{L}$ and $20 \mu \mathrm{g} / \mathrm{L}$ for the freshwater discharges, respectively, for copper and zinc, and $7 \mu \mathrm{g} / \mathrm{L}$ and $6 \mu \mathrm{g} / \mathrm{L}$ for the sea boundary, following the values reported in Table 1 and suggested by Stevenson and Betty (1999).

The year 2006 was selected as a reference to develop the numerical model, due to the largest amount of data being available for this year. For setting the initial conditions, we performed preliminary simulations which lead to regime hydrodynamic conditions, i.e. a simulation where fixed tidal amplitude and riverine discharge were repeated until two consecutive tidal cycles give the same periodic result in terms of salinity distribution. The assumed tide and discharge were representative of average conditions of the estuary. Starting from this state, numerical simulations were run from November 2005, using the first two months as a spin-up period. Thanks to the spin-up period, initial conditions had no significant influence on the results. Regarding the water quality model, we started from average conditions obtained by the available measurements, and the output of the spin-up months was used to initialize the period under investigation.

The model was calibrated by comparing measured and computed quantities and varying the parameters using a trial-and-error strategy based on 'expert' judgement. Bias, mean absolute error, root mean square error and correlation $(\rho)$ were evaluated to select the parameters. Most of the parameters were obtained referring to the simulated year 2006, but some water quality parameters were calibrated considering also the results obtained for the higher temporal resolution dataset in February and August 2011. Roughness values were determined considering the sediment distribution (Baugh et al. 2013; Prentice 1972; Mitchell et al. 2012; Lavery and Donovan 2005) and evaluating the response of the model to changes in these parameters. Horizontal diffusivity and viscosity were assumed identical and dependent on the grid cell area to account for the correct amount of mixing, which can influence diffusive (Okubo 1971) and hydrodynamic processes (Toffolon and Rizzi 2009, 2013). The assumption of variable values along the estuary was necessary to obtain realistic longitudinal profiles of salinity (see details in Supplementary Material).

The model was used to reproduce the estuary behaviour for the entire year 2006, but the evaluation of the model and the analysis of the results were focused on three representative months (February, July and December), selected as typical of mean, low and high river discharge, respectively. To analyze the influence of the initial conditions on the final results, three additional single-month simulations were run starting from a regime condition and compared with the months extracted from the whole-year simulation. Finally, the model was compared to the data available with higher temporal resolution in February and August 2011, which were run as single-month cases. Thanks to the higher resolution, the dynamics of resuspension and sedimentation were analyzed more in detail, showing differences between the ebb and flood phase which cannot be highlighted using the coarser dataset.

Further details of all the procedures considered in the calibration and validation of the model are provided in the Supplementary Material.

\section{Results}

\section{Exploratory Data Analysis}

Main drivers of metal fate in the Thames Estuary have been identified by the performed statistical analysis. An overview of the longitudinal distribution of salinity, suspended solids, copper and zinc along the estuary is given in Fig. 2. The salt intrusion curve presents a regular 'half-bell' shape, with the limit of the salinity intrusion length located between Barnes $(x=-17.7 \mathrm{~km})$ and London Bridge $(x=0 \mathrm{~km})$. Salinity is subject to significant variations especially in the central part of the estuary. The total suspended solids show a maximum (ETM) in Gravesend $(x=42.5 \mathrm{~km})$ and a region of high turbidity in the upstream reach up to London Bridge $(x=0-26.9 \mathrm{~km})$. TSS concentrations are small both in the freshwater area and in the nearshore area. It is worth noting that the concentration range is wide especially in the central part. Minimum concentrations are usually close to zero and outliers with very high concentrations can occur in the Mud Reaches. Also, metal concentrations are 
Fig. 2 Box plots for a salinity, b total suspended solids, $\mathbf{c}$ total copper and $\mathbf{d}$ total zinc concentration in the estuary, using all available data (period 2003-2011 for salinity, and 2002-2009 for the other three quantities). Lines represent the average values during spring and neap tide (solid and dashed lines). Red crosses represent outliers
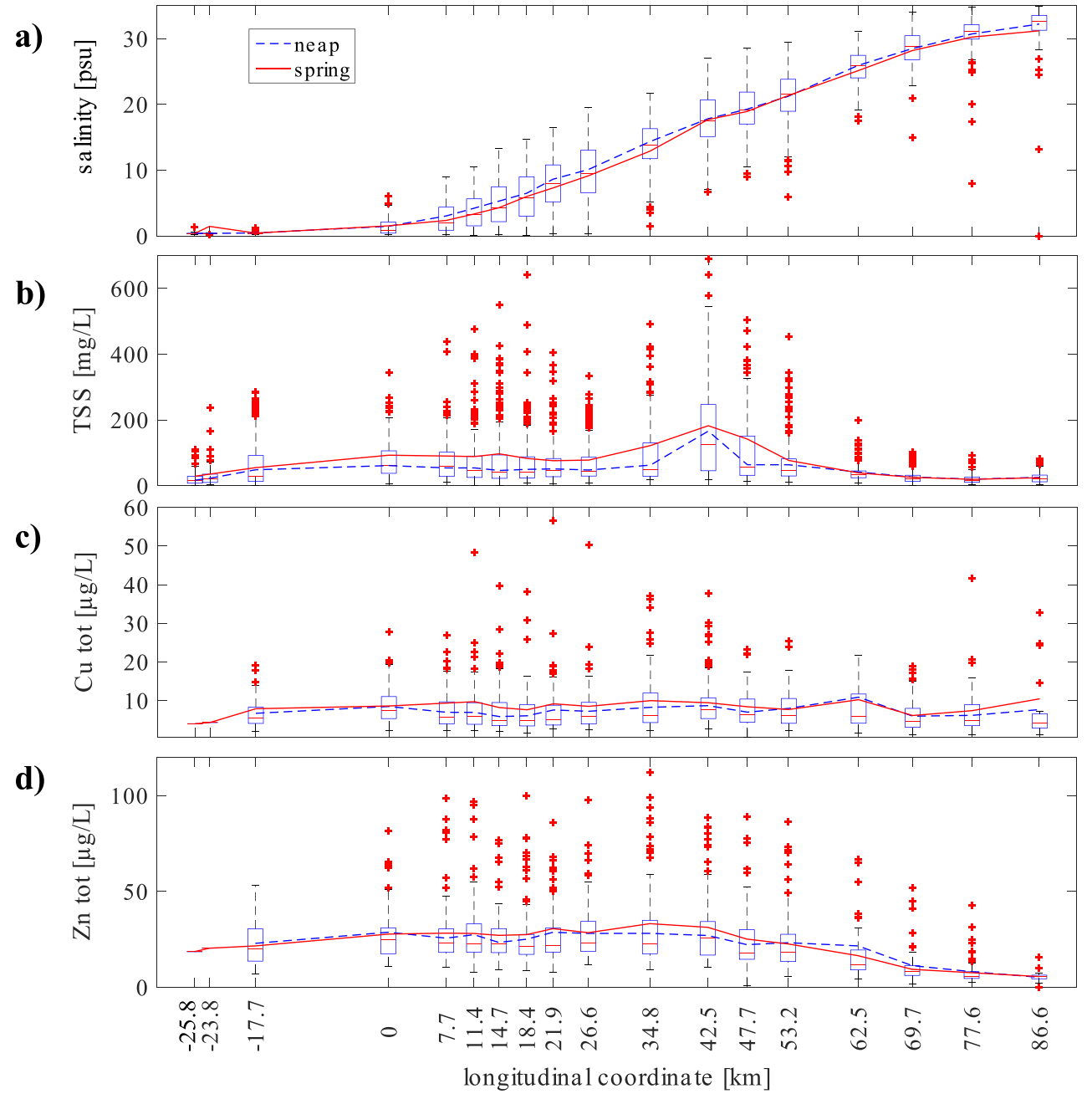

usually higher in the central part of the estuary. Peaks in concentrations are related both to sediment resuspension and anthropogenic inputs from the adjacent city of London (Power et al. 1999; Pope and Langston 2011). Zinc, in particular, presents local peaks where TSS concentration is higher, while copper shows a more uniform behaviour throughout the estuary. The tidal forcing effects on metal fate are also presented in Fig. 2 by separating spring and neap tides. Among all parameters, suspended solids concentration is the most influenced by the tide, showing higher concentration during spring tide. Salinity, copper and zinc do not appear to be strongly influenced by tidal range variations. However, metals seem to correlate with TSS, displaying higher concentrations during spring tide, while salinity presents a slight opposite trend. Thus, contaminated particles are easily resuspended during tidal cycles.

The correlation coefficient $\rho$ and $p$ value matrices among the relevant parameters are reported in Table 2 . Salinity shows a weak negative correlation with suspended solids and discharge, suspended solids and total metal concentrations are weakly positively correlated, while the strongest correlation exists between the concentrations of the two analyzed metals. Taking altogether, this strongest correlation confirms that similar environmental fate processes are of major relevance for metal pollution within the estuary. Metal concentrations present limited influence of salinity or discharge (Förstner and Wittmann 2012), a result that supports the non-conservative behaviour, which is very common for metals (Paquin 2003; Loder and Reichard 1981).

Analysing each observation point separately (not shown), the correlation between suspended solids and metal concentrations becomes higher in the Mud Reaches area (for instance in Gravesend $\rho=0.48$ for TSS-Zn and $\rho=$ 0.66 for TSS-Cu), i.e. the highest concentrations of trace metals in the water coincide with high turbidity zones in the middle region. This highlights the role of resuspension and sediment remobilization due to tidal forcing as a critical driver of pollution in contaminated areas.

Figure 3 shows the opposite trend of suspended solids concentration and freshwater discharge in London Bridge, where the salinity decreases. It could be expected that 
Table 2 Correlation matrix for monthly averages of the main parameters ( $p$ values are reported in parentheses)

\begin{tabular}{|c|c|c|c|c|c|}
\hline & Q & TSS & SAL & $\mathrm{Cu}$ & $\mathrm{Zn}$ \\
\hline $\mathrm{Q}$ & $1(-)$ & $0.079(0.020)$ & $-0.181(<0.001)$ & $-0.103(0.002)$ & $-0.042(0.218)$ \\
\hline TSS & & $1(-)$ & $-0.271(<0.001)$ & $0.266(<0.001)$ & $0.394(<0.001)$ \\
\hline SAL & & & $1(-)$ & $-0.010(0.775)$ & $-0.374(<0.001)$ \\
\hline $\mathrm{Cu}$ & & & & $1(-)$ & $0.651(<0.001)$ \\
\hline $\mathrm{Zn}$ & & & & & $1(-)$ \\
\hline
\end{tabular}

higher freshwater discharge, producing higher bed shear stress, may lead to increased resuspension. Conversely, TSS increases during drought periods, a behaviour already highlighted by Mitchell et al. (2012). Indeed, the ETM magnitude increases with increasing tidal range as a consequence of enhanced sediment resuspension, and decreases with increasing freshwater flow, presumably because of both decreased speeds of flood tidal current (reduced resuspension in a flood-dominated estuary) and down-estuary movement of the salinity distribution. Furthermore, under high freshwater flow, the sediments are moved downstream from the seaward net flux of water. After periods of high freshwater flushing, fine sediments can also become unavailable for resuspension.

\section{Numerical Model}

The results of numerical simulations were compared against the available data by means of scatter plots (Fig 4). The agreement is especially good for the hydrodynamic results, i.e. water level and salinity. Larger deviations appear for suspended solids and metal concentrations. These are expected given some uncertainties in input values and boundary conditions, which were kept fixed for the inputs from the River Thames and the sea (see "Implementation of the Model"), since high-frequency data were missing. Information about the River Medway and possible inputs from London City was also missing. The intrinsic difficulties in the proper description of the relevant processes, limited by the absence of velocity measurements, prevented a more complete model calibration. We refer to "Discussion" for a discussion about this and other limitations.

The analysis of water levels is shown in Fig. 4a, separately for each station. Excluding some outliers, which are due to few erroneous measurements by the tidal gauge (please refer to the Supplementary Material for more details), the simulation results agree with measured data for all stations. The only exception is Richmond, where the model tends to overestimate the steepening during the flood phase. Indeed, the tidal wave becomes asymmetric when it propagates from downstream to upstream. In this upstream section the rise of water level is sharper than the fall, especially when compared with more seaward stations (e.g. Southend), where the wave has an approximately sinusoidal shape (Fig. 5). The steepening is visible both in the measured and computed water levels, but the emphasized behaviour in the modelled wave determines larger errors in the correlation calculation. Figure 5 also reports on the distortion of the tidal wave, which is amplified from the sea to London Bridge and damped from London Bridge to Teddington due to the combined effect of friction and bank convergence (Mikhailov and Mikhailova 2012). Velocity variations are characterized by the same dynamics, with more irregular patterns in the upstream part showing a strong tidal asymmetry. In particular, at Richmond the velocity has large negative (flood) peaks, which can be responsible for increased resuspension. Additionally, it is important to mention that Richmond is located close to Teddington and Richmond Locks, which were not modelled but might affect the real water level and velocity.

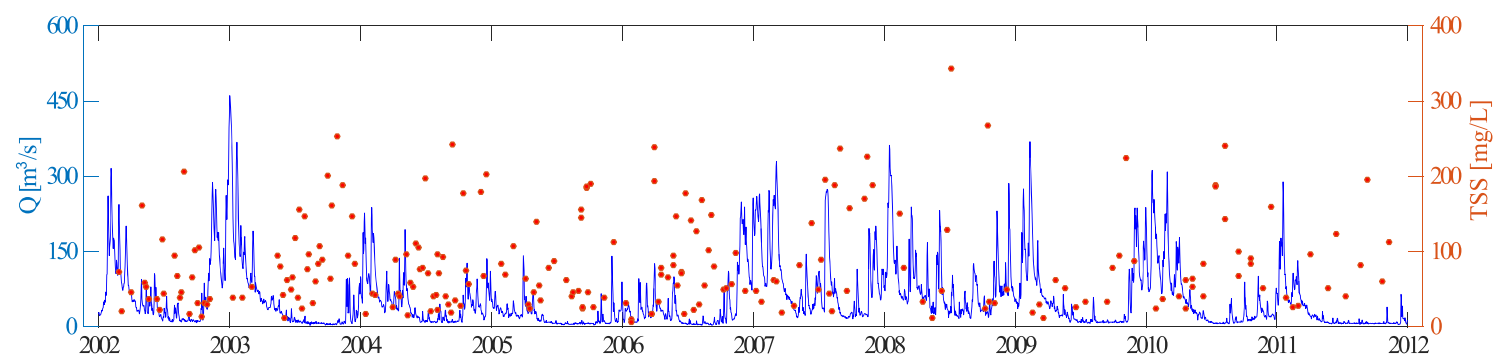

Fig. 3 Temporal records of freshwater discharge (Q, line) and suspended solids (TSS, circles) measured at London Bridge (longitudinal coordinate $=0 \mathrm{~km}$ ) 
Fig. 4 Scatter plots between modelled and measured values of a water level, $\mathbf{b}$ salinity, $\mathbf{c}$ TSS, $\mathbf{d}$ total copper and $\mathbf{e}$ total zinc concentration, in the estuary for a one-year simulation (2006) a)
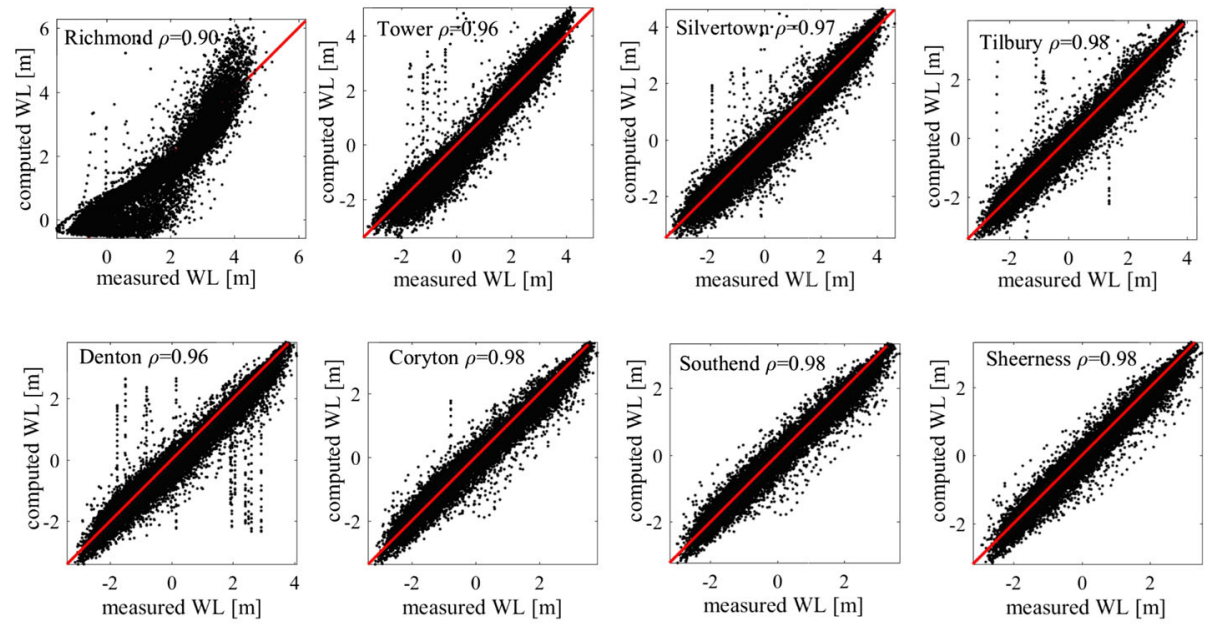

b)

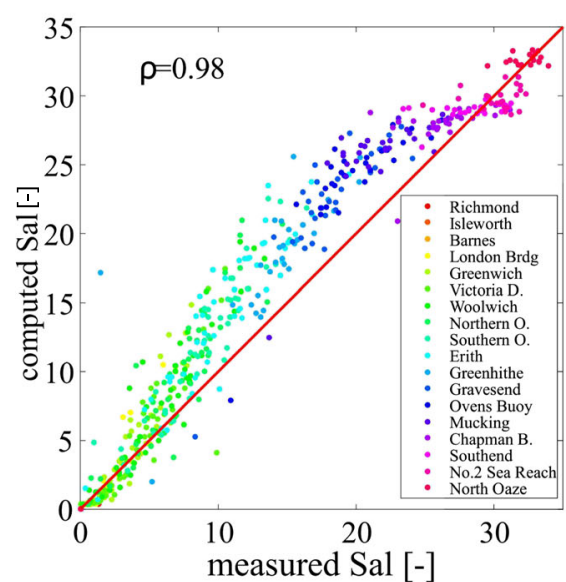

d)

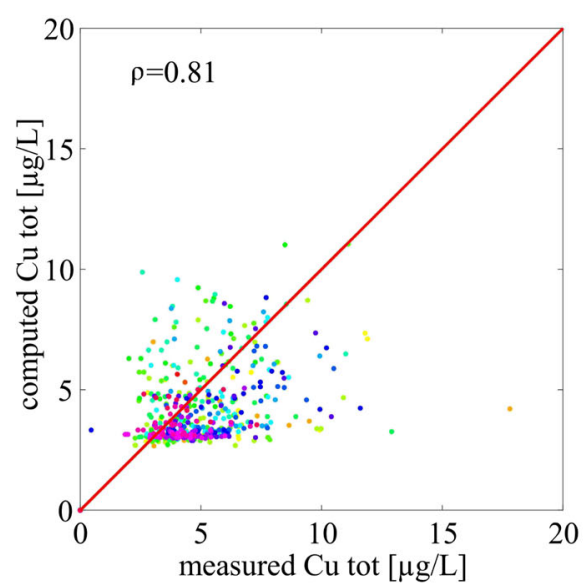

e)
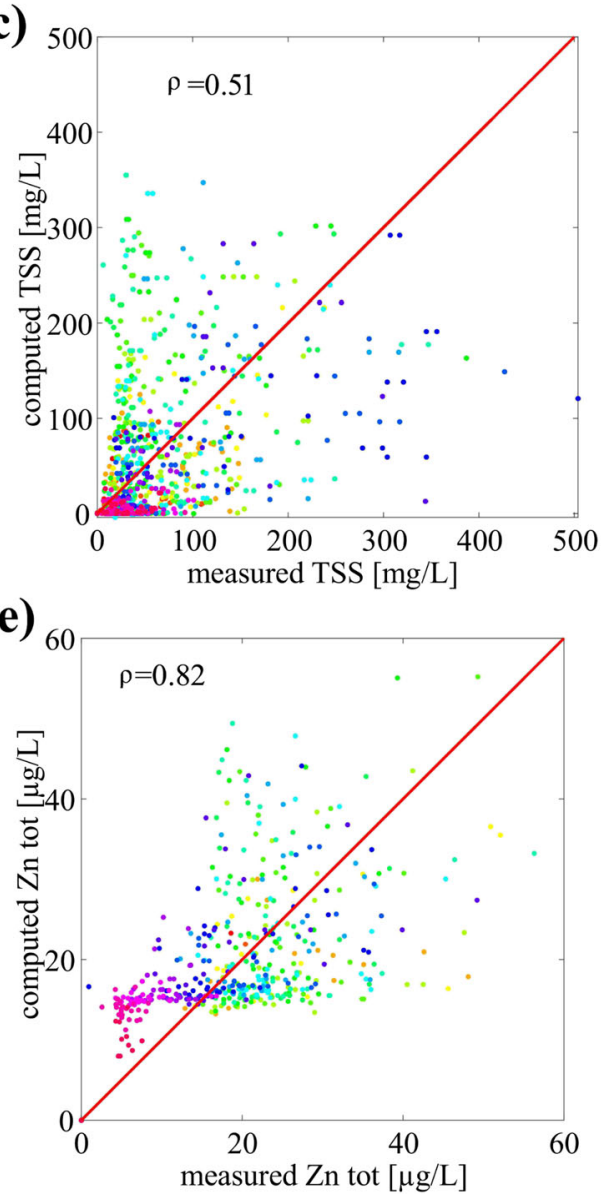

At the observation points (Fig. 4b), salinity is plotted as depth-averaged values, because it does not show significant differences between surface and bottom values, as expected since the Thames is well mixed. Computed salinity shows good agreement with the measured values, with an overestimation only in the central part of the estuary, which is likely related to unaccounted freshwater inputs from combined sewer overflows. TSS and metal concentrations are also analyzed as depth-averaged values (Fig. 4c-e). Although in this case substantial differences occur between surface and bottom concentrations, no information about the exact position of the measuring instruments was available. Moreover, there was a lack of a systematic procedure for collecting TSS data at the same time in the tidal cycle. 

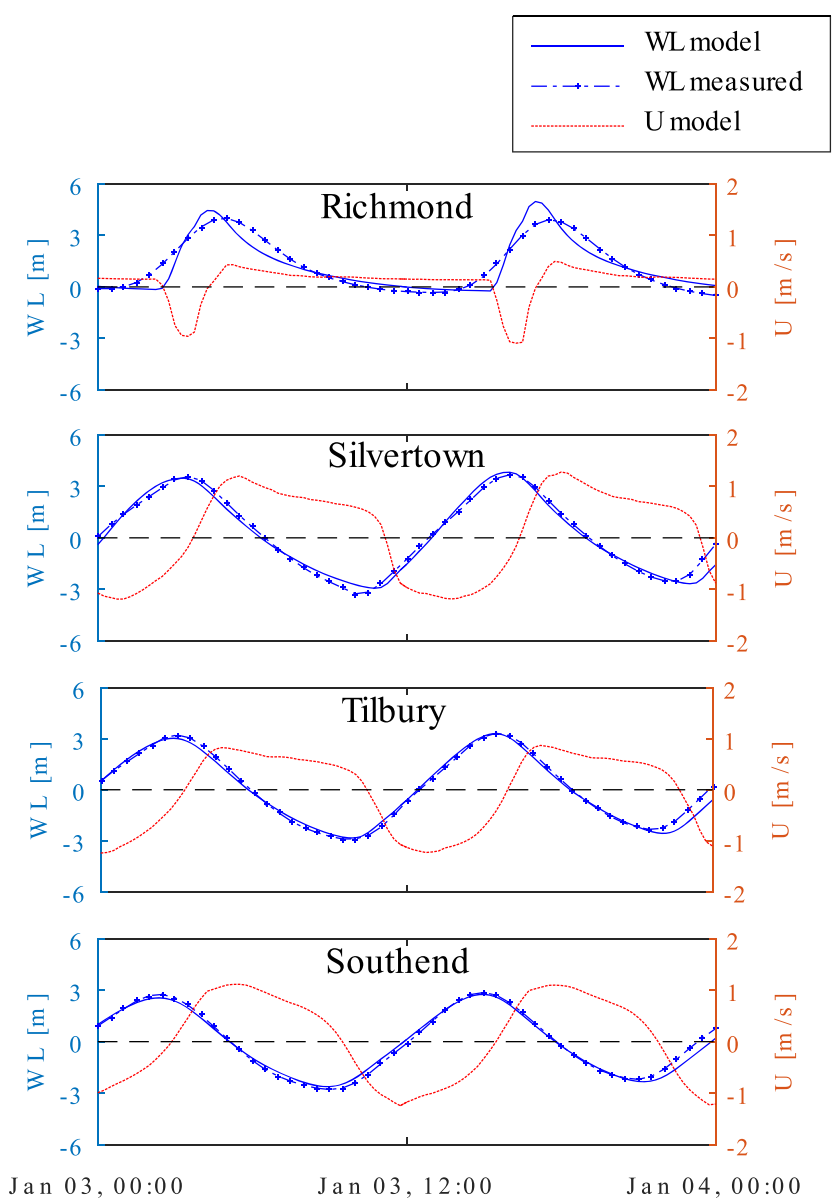

Fig. 5 Water level (measured and modelled) and velocity (modelled) at different observation points within the estuary on a specific day (3 January 2006)

Thus, while the hydrodynamic model is accurate, the results are not so satisfactory regarding TSS (Fig. 4c). The correlation coefficient has a lower value and no trends or systematic errors are visible with both over- and underestimation in many locations, especially in the central part of the estuary. Despite the evident lack in terms of the accuracy of the water quality model, the model is able to reproduce the correct range of variation of the reproduced parameters. Better correlation is shown for the two metals, but the same concerns are valid because their dynamics are strongly influenced by TSS.

However, model results highlight how metal concentrations strongly depend on sediment resuspension. Higher concentrations in the central part of the Thames Estuary are confirmed both by observed and modelled trends. It follows that a decrease in the inputs of metals from freshwater and sewage sources would not immediately affect the level of pollution of the estuary. The role of resuspension due to tidal forcing turns out to be a key process in such a system, resulting in a long-term source of pollution.

\section{Sub-tidal Variability of TSS}

In order to address the concerns related to the scatter of the TSS correlation, the model was also compared with the data collected at higher temporal resolution in February and August 2011. Figure 6 shows the results for Chelsea, located in the upstream Thames, and Purfleet, in the Mud Reaches. The two months mainly differ because of the freshwater discharge, which was higher in February than in August.

At Chelsea, measured TSS concentrations are lower in February than in August. According to the mechanistic inference from Fig. 3, sediments were moved downstream during months of higher discharge, thus producing lower TSS concentrations. In the model outputs, the response to changes in river discharge is not as relevant as expected, at either station. For Chelsea, there is a tendency for the model to underpredict the amount of settling that occurs during the slack water periods, causing (in February) a lack of available sediment for resuspension each tide (Fig. 6a).

At Purfleet, differences were negligible between the two months, with slightly higher concentrations registered in February. The patterns in the shape of measured and computed concentrations are more similar in this case. In particular, the reduction in concentration during the sedimentation phase is characterized by the same slope, suggesting that the settling flux is reasonably well simulated. Additionally, the range of variation is approximately the same, and in both cases, the concentration drops to close to zero. However, the model shows a delay, which can be clearly observed at Purfleet. Especially in the ebb phase, concentration does not increase instantaneously with increasing bed shear stress as it does for the measured values. Interestingly, the dynamics modelled on the right bank (green lines in Fig. 6b, d, i.e. a location opposite to where the measurements were actually taken) shows better agreements with measured data. A possible explanation is the excessive secondary circulation simulated by the model because of a sequence of two sharp bends at Purfleet (see Fig. 1).

\section{Effects of Tides and Freshwater Discharge on the Large-scale Dynamics}

The overall response of the Thames Estuary to different forcing conditions was considered using three specific months in 2006: February, July and December, characterized by mid, low and high values of freshwater discharge, respectively. The individual analysis of these three periods facilitates the evaluation of the effect of the riverine discharge. Figure 7 shows the envelopes of water level, longitudinal velocity and salinity for the three months. Velocity and salinity are calculated as averages over the water column in the point of maximum depth in each section. 
Fig. 6 Comparison between model results and measurements of TSS at Chelsea $(\mathbf{a}, \mathbf{c})$ and Purfleet (b, d), in February (a, b) and August (c, d) 2011. Modelled bed shear stress is also indicated using the secondary axis

\section{- computed shear stress \\ -.-m measured TSS \\ computed TSS \\ + computed TSS right bank}

a)

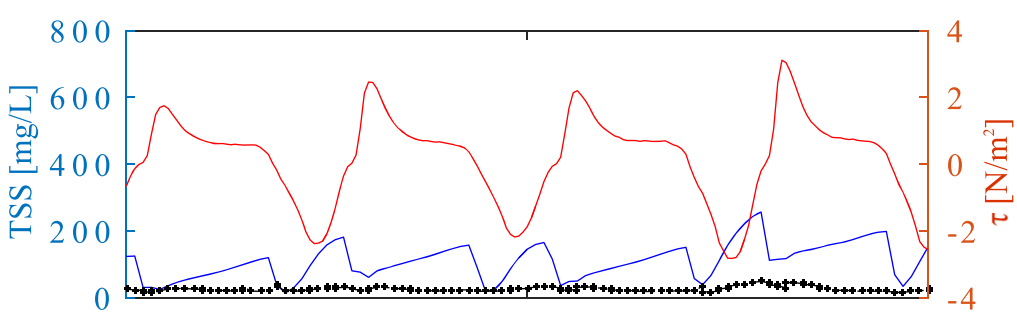

b)

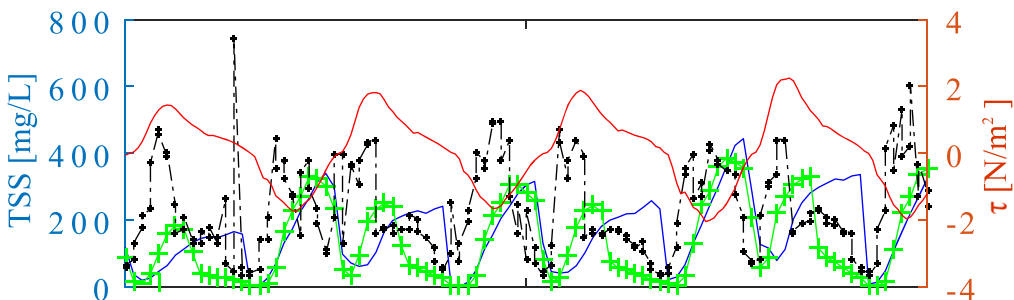

Feb 17

Feb 18

Feb 19

c)

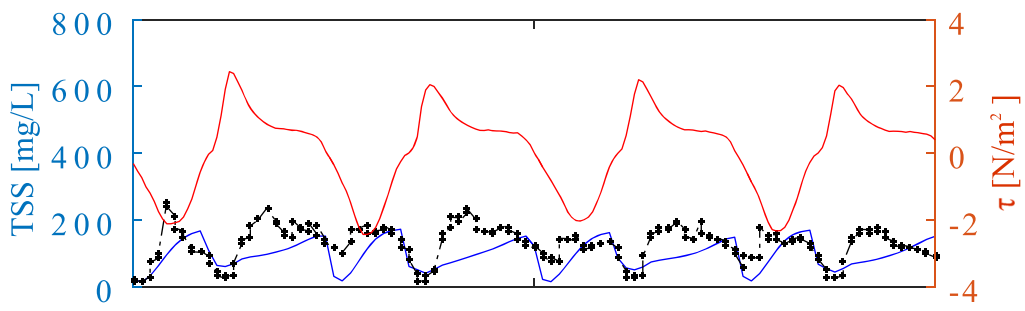

d)

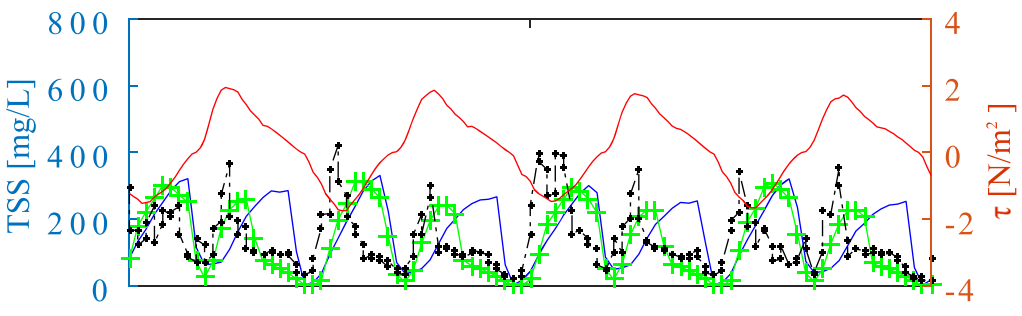

Aug 18

Aug 20
Water level is influenced both by freshwater discharge and tidal amplitude (Fig. 7a). The influence of freshwater discharge is visible at the minimum water level in the upper part of the estuary. The highest minimum occurs during the month of higher discharge, while the lowest during the dry month. Conversely, the highest maximum occurs in February, when the tidal range was especially high (see Figure S4 in the Supplementary Material). Longitudinal velocity does not show important differences (Fig. 7b), except for the upstream region where large peaks occur in February and July for negative (flood) velocities. These peaks are related to the asymmetry of the tidal wave, which is stronger in the upstream estuary leading to high bed shear stress in that area. Salinity envelopes show that the model correctly reproduces the movement of the salt intrusion limit
(Fig. 7c). It shifts upstream during the driest month (July), while it moves downstream in December, in accordance with measured data that fall within the envelopes except for some isolated points.

Figure 8 shows the distributions of TSS and metals (depth-averaged concentrations) along the estuary for the whole of 2006. Results are presented separately for neap and spring tide, and show clear differences in the two periods. The effect of freshwater discharge is taken into account by considering the same three representative months of the year as above. The major effect on TSS may be caused by the tide, because in February the maximum concentration occurs during spring tide (Fig. 8a) and the minimum during neap tide (Fig. 8b). This trend is amplified in February by the fact that the tidal range is higher during spring 
Fig. 7 Envelopes of modelled quantities in three significant months of year 2006 for a water level, b longitudinal velocity and $\mathbf{c}$ salinity. Continuous lines represent minimum and maximum values, and dashed lines represent mean values. Coloured dots represent measurements
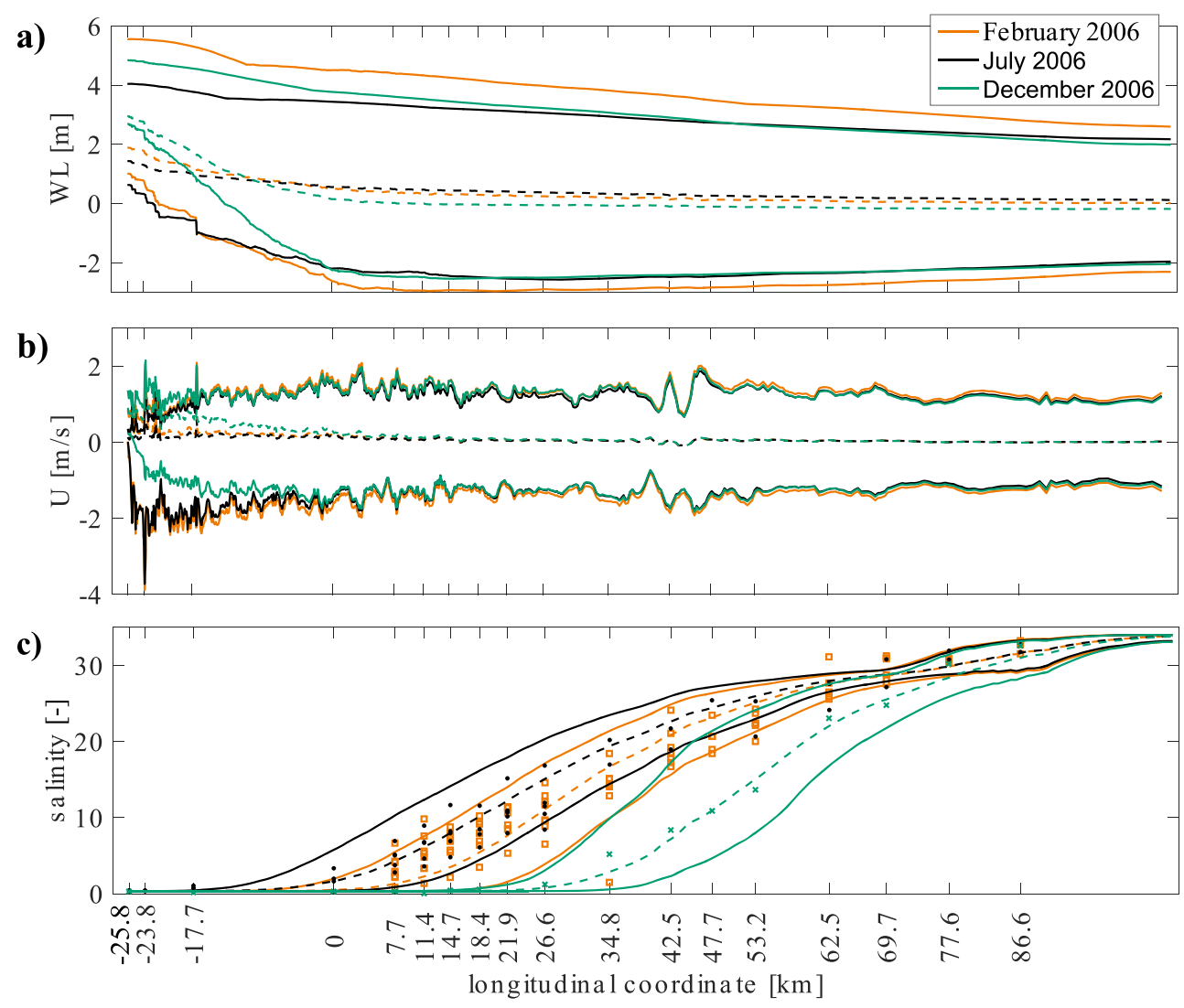

tides and lower during neap tides compared to the other two months (Figure S4 in the Supplementary Material). The first upstream reach seems to be influenced also by freshwater discharge, which produces higher resuspension in December when the velocity and bed shear stress are higher than in the other months. The modelled ETM is approximately located in the so-called Gallion's Reach (Southern Outfalls), and not in Gravesend as suggested by measurements, but high concentrations are simulated in the entire area of the Mud Reaches. Similar observations are valid also for metal concentrations, which also show a maximum in the Mud Reaches due to resuspension of metals attached to sediment (Fig. 8c-f). The high concentrations in the regions close to the river and sea boundaries, and especially for copper, are due to the inputs of the pollutants that are assumed as boundary conditions.

\section{Discussion}

\section{Performances of the Model}

The previous analyses show that the model performs well in reproducing the hydrodynamic quantities (water level) and the salinity intrusion. Unfortunately, the absence of velocity measurements limits a complete calibration of the hydrodynamic model and can affect the set-up of the water quality part. In fact, some uncertainties were revealed regarding the water quality model, especially for suspended solids. In this section, the main results are discussed to provide further insights on the dynamics of such a complex environment.

The first important limitation is that the numerical simulation covers only a limited time period. Especially for the quantities related to water quality parameters and sediments, the actual distribution of the concentration strongly depends on the memory of the system. For example, the process of salinization in an estuarine system, i.e. the gradual replacing of freshwater by saline water through mixing (Savenije 2012), takes time. The time needed is heavily related to the salinity distribution assumed as the initial condition for the simulation, which can lead to a different system response if the duration is too short. For instance, comparing single-month versus one-year simulations in Erith (see Figure S7 in the Supplementary Material), the salinity modelled in the short simulation is underestimated in December (high discharge), a condition that also affects TSS and metals, while the differences are almost irrelevant in July (low discharge). As a general recommendation to obtain accurate results, the duration of 
Fig. 8 Box plots of TSS and metals in the water quality observation points for 2006: a and $\mathbf{b}$ TSS, $\mathbf{c}$ and $\mathbf{d}$ total copper, $\mathbf{e}$ and $\mathbf{f}$ total zinc, considering spring (a, c, e) and neap tides (b, d, f). Dashed lines represent mean values for three representative months (February, July and December 2006). Coloured dots represent measurements. Note that the range in the vertical axis is different for spring and neap tides a)

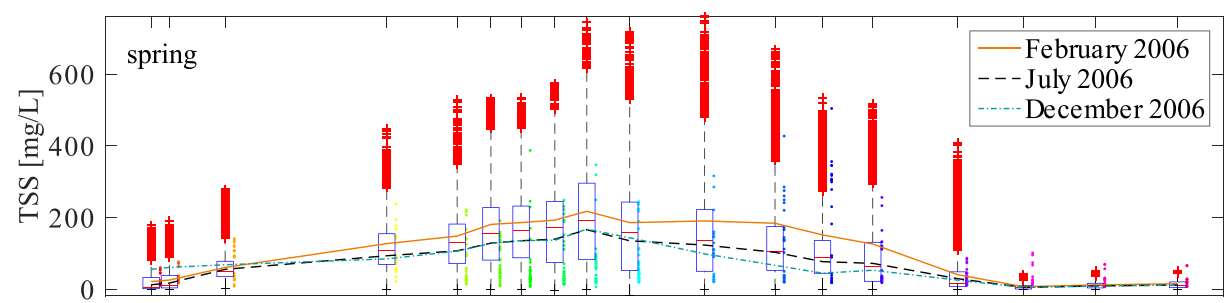

b)

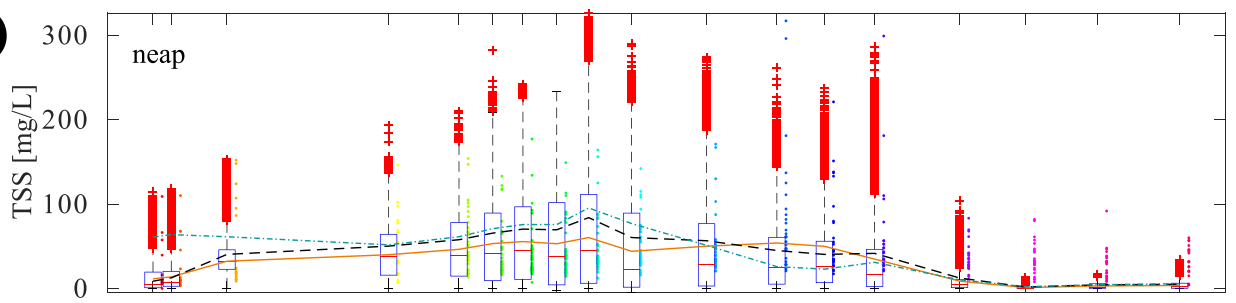

c)

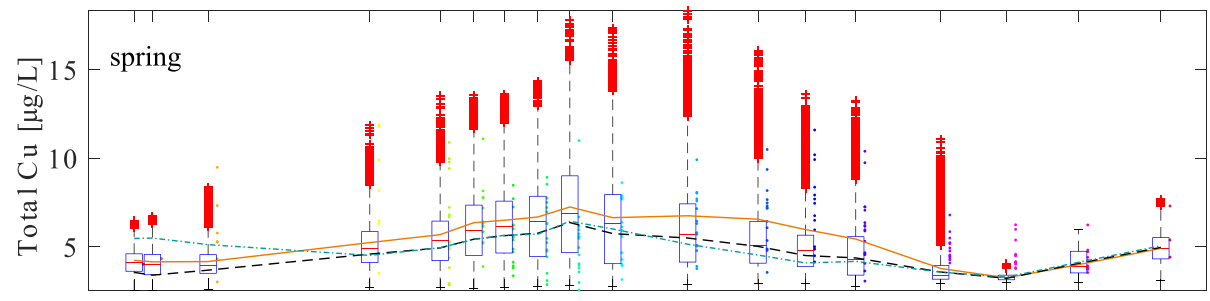

d)

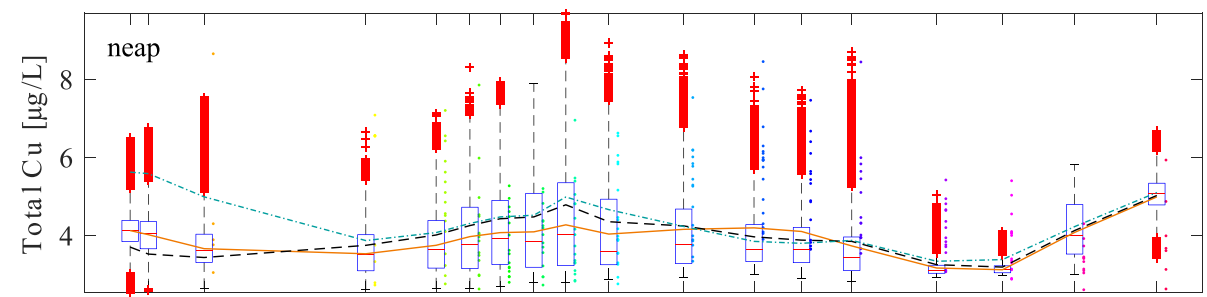

e)

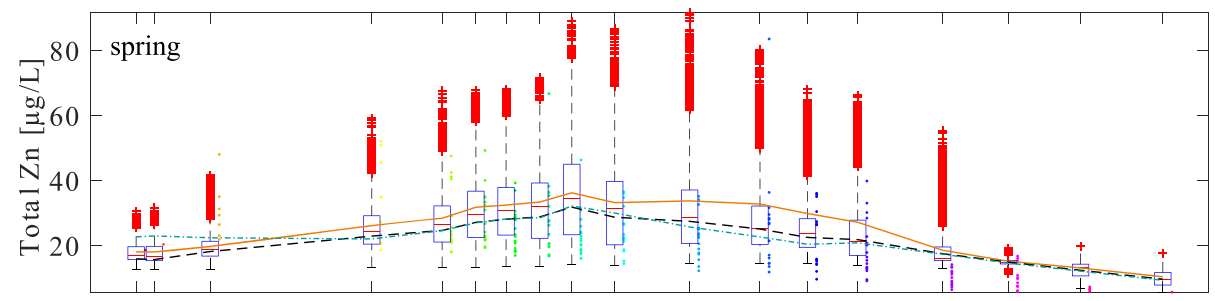

f)

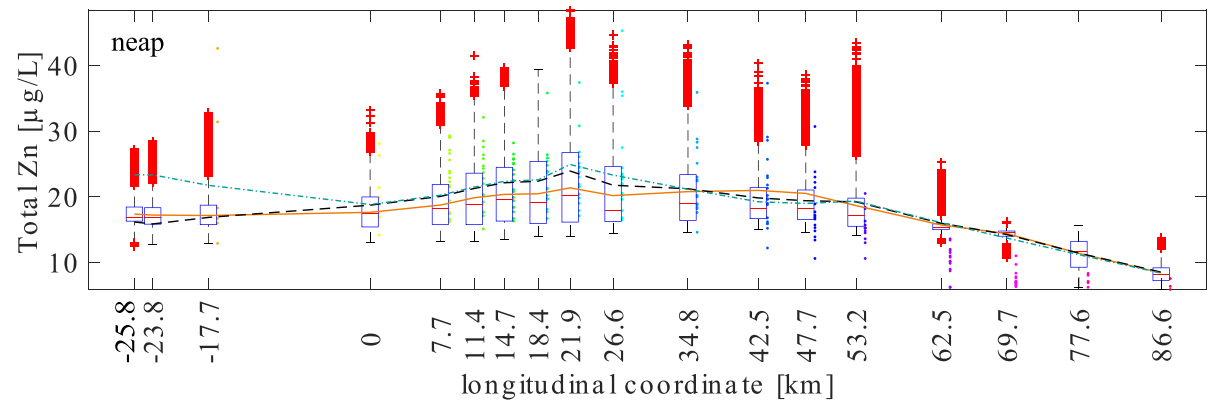

the simulations should be carefully designed to reduce the influence of the initial conditions, which can be very long for salinity and, in turn, for other transported quantities.

A second important issue is the vertical variability of the simulated concentrations. The analyses comparing computed and measured data were based on averages of the water column because, as already discussed, no information was available on the sampling depth. However, important differences exist between the concentration at the bottom and in the surface layer for TSS and metals, which are in principle reproduced by a 3D model, but currently there are no data available to validate the results. Furthermore, pollution sources deriving from, e.g. surface runoff, urban drainage, sewage treatment plants, domestic 
sewage, industrial wastewater discharge or agricultural activities (Neal et al. 2004; Attrill and Thomes 1995; Power et al. 1999) from local urban areas were neglected, but are likely to be important.

The scarceness of accurate information strongly affects the set-up of the model. Nevertheless, the model can help to optimize the spatial and temporal design of field studies to reduce data gaps for mass balances and to consider hydrologic dynamics. In spite of the limitations discussed above, we can conclude that the hydrodynamic and water quality modules implemented in the numerical model reproduced realistic environmental data. For this reason, the results can help in understanding the large variability of the mechanisms affecting the estuary, even if not completely accurate. In fact, the available measurements present significant gaps and inconsistencies given the intrinsic difficulties in setting up a continuous monitoring system. Additionally, the in situ observations are representative of local conditions. Hence, a 3D model has the added value of being able to reproduce a complete overview of the system in a relatively short time. With this tool, we could be able to efficiently and accurately plan which parameters need to be monitored, when and where, for example the difference highlighted by the model between the right and left bank ("Sub-tidal Variability of TSS"), which would need to be confirmed by in situ measurements.

Future improvements should mainly regard the complexity of sediment transport processes and the data available to calibrate and validate the model. For instance, some simplifications introduced in the model, e.g. neglecting flocculation and diversity of suspended solids, were consequences of the lack of information regarding sediment size distributions. Considering these additional factors might improve the prediction of sediment concentrations during ebb and flood phases.

In conclusion, the numerical model was able to reproduce the correct range of variation of observed total suspended solids and total metal concentrations. We demonstrated that the Thames Estuary is very sensitive to variations of the tide: neap and spring tides lead to lower and higher suspended solids and metal concentrations, respectively. The effects of changes in freshwater discharge are instead more appreciable observing the distribution of salinity, whereas a lack of sensitivity was found in the sediment transport model compared with observed data. In general, the principal estuarine mechanisms, like the position of the salinity front or the presence of the estuarine turbidity maximum, were well represented. It is important to note that detailed understanding of the model and its advantages and drawbacks is only possible by considering the details of individual tidal cycles for high and low freshwater flow, given the impact of this variable especially upstream of London Bridge.

\section{Generalization of the Results}

The Thames Estuary constitutes a very complex environment, and the dynamics that contribute to transport, resuspension and sedimentation of sediments are not fully understood. The inherent complexities of erosion and deposition processes, especially regarding the influence of flocculation and other biogeochemical processes, may strongly affect the modelling of metals, as well. In this respect, fundamental uncertainties arise from insufficient information on the spatial distributions of metals and bed sediments. All these issues, mostly due to the lack of observational data to calibrate and validate a complex 3D model, can yield significant uncertainties especially in the water quality results.

The findings presented here are of clear relevance to other similar systems and the modelling strategies presented in the literature to date. However, the Thames is also different to similar heavy industrialized estuaries in the relative lack of restoration measures (Stark et al. 2017) due to lack of available space and due to the inherent nature of the management systems and governance processes. This implies a need for development of the present strategy of linking the fate of metals with that of the sediments, clearly of interest given the likelihood of both of remaining in the larger system for longer periods than might be the case if the sediments and metals were released from the system. In all similar cases though, information on the fate of metals and the link with sediments must form part of the ongoing development of modelling approaches.

\section{Conclusions}

This study investigated the hydrodynamics and water quality of the Thames Estuary through monitoring and numerical modelling. The Thames is an industrialized and engineered macrotidal estuary and as such requires detailed data to illustrate the processes that govern its response to changes in environmental and anthropogenic factors. With the purpose of better understanding sediment and metal fate, the whole year 2006 was simulated by means of a threedimensional model. Complex physical processes affecting metal fate were observed to arise from the interaction of the two main driving forces, i.e. the freshwater discharge and the tide. An exploratory analysis on the available data revealed the non-conservative behaviour of metals as well as the presence of a correlation between metal and total suspended solids concentrations.

Model results reinforce that the fate of metal contaminants strongly depends on sediment resuspension leading to higher concentrations in the central part of the Thames Estuary. The role of resuspension due to tidal forcing in that critical area constitutes a key process affecting metal 
aqueous concentrations. Even considering future trends of reduced input of metals from freshwater or sewage sources due to more restrict environmental regulations, metal accumulation in the sediments will remain an important sink, but also long-term source of pollution.

In the attempt to evaluate long-term trends, 3D models can now be considered affordable tools, and the main limitation is the availability of data to calibrate the parameters and to validate the outputs of the simulations. As soon as more observations will be available, the accuracy of the model results will increase and the final goal of investigating the fate of metals in the Thames Estuary under different climate change scenarios could be eventually reached.

These results are important in terms of our understanding of the fate of metals in all similar industrialized macrotidal systems. Where possible, the use of models to relate sediment transport to metal concentrations should be applied in such systems to assess the impacts of any changes that may affect the ways in which they function.

Acknowledgements We gratefully acknowledge the Port of London Authority and the Environment Agency of England and Wales for providing the data analyzed in this study. This research was partially supported by the Leibniz-Institute of Freshwater Ecology and Inland Fisheries (IGB, Germany). Abel Machado collaborated with this project thanks to the Erasmus Mundus Joint Doctorate Program SMART (Science for MAnagement of Rivers and their Tidal systems) funded with the support of the EACEA of the European Union. We thank Katherine Cronin (Deltares), who provided precious insights and expertise in setting the model.

\section{References}

Attrill, M.J., and R.M. Thomes. 1995. Heavy metal concentrations in sediment from the Thames Estuary, UK. Mar Pollut Bullet 30(11):742-744.

Attrill, M.J., S.D. Rundle, and R.M. Thomas. 1996. The influence of drought-induced low freshwater flow on an upper-estuarine macroinvertebrate community. Water Res 30(2):261-268.

Baugh, J.V., and M. Littlewood. 2005. Development of a cohesive sediment transport model of the Thames Estuary. American Society of Civil Engineers.

Baugh, J., N. Feates, M. Littlewood, and J. Spearman. 2013. The fine sediment regime of the Thames Estuary-a clearer understanding. Ocean Coast Manag 79:10-19.

Baugh, J.V., and A.J. Manning. 2007. An assessment of a new settling velocity parameterisation for cohesive sediment transport modeling. Cont Shelf Res 27(13):1835-1855.

Benoit, G., S. Oktay-Marshall, A. Cantu, E. Hood, C. Coleman, M. Corapcioglu, and P. Santschi. 1994. Partitioning of $\mathrm{Cu}, \mathrm{Pb}, \mathrm{Ag}$, $\mathrm{Zn}, \mathrm{Fe}, \mathrm{Al}$, and $\mathrm{Mn}$ between filter-retained particles, colloids, and solution in six Texas estuaries. Mar Chem 45(4):307-336.

Bianchi, T.S. 2006. Biogeochemistry of estuaries. Oxford: Oxford University Press.

Boyle, E., R. Collier, A. Dengler, J. Edmond, A. Ng, and R. Stallard. 1974. On the chemical mass-balance in estuaries. Geochim Cosmochim Acta 38(11):1719-1728.
Cai, H., H.H.G. Savenije, and M. Toffolon. 2012. A new analytical framework for assessing the effect of sea-level rise and dredging on tidal damping in estuaries. J Geophys Res 117:C09023. https://doi.org/10.1029/2012JC008000.

Chauchat, J., S. Guillou, N. Barbry, and K.D. Nguyen. 2009. Simulation of the turbidity maximum in the Seine estuary with a two-phase flow model. C R Geosci 341(7):505-512.

De Brye, B., A. de Brauwere, O. Gourgue, T. Kärnä, J. Lambrechts, R. Comblen, and E. Deleersnijder. 2010. A finite-element, multiscale model of the Scheldt tributaries, river, estuary and ROFI. Coast Eng 57(9):850-863.

de Jonge, V.N., H.M. Schuttelaars, J.E. van Beusekom, S.A. Talke, and H.E. de Swart. 2014. The influence of channel deepening on estuarine turbidity levels and dynamics, as exemplified by the Ems estuary. Estuar Coast Shelf Sci 139:46-59.

de Souza Machado, A.A., K. Spencer, W. Kloas, M. Toffolon, and C. Zarfl. 2016. Metal fate and effects in estuaries: a review and conceptual model for better understanding of toxicity. Sci Total Environ 541:268-281.

de Souza Machado, A.A., K.L. Spencer, C. Zarfl, and F.T. O'Shea. 2018. Unravelling metal mobility under complex contaminant signatures. Sci Total Environ 622:373-384.

Förstner, U., and G.T. Wittmann. 2012. Metal pollution in the aquatic environment. Springer Science \& Business Media.

Gourgue, O., W. Baeyens, M. Chen, A. de Brauwere, B. de Brye, E. Deleersnijder, M. Elskens, and V. Legat. 2013. A depth-averaged two-dimensional sediment transport model for environmental studies in the Scheldt Estuary and tidal river network. J Mar Syst 128:27-39.

Hobbie, J.E. 2000. Estuarine science: a synthetic approach to research and practice. Island Press.

Intergovernmental Oceanographic Commission. 2003. International Hydrographic Organization, and British Oceanographic Data Centre. Centenary Edition of the GEBCO Digital Atlas.

Jay, D.A. 1991. Green's law revisited: tidal long-wave propagation in channels with strong topography. J Geophys Res 96:20:58520:598.

Knaapen, M., and D.M. Kelly. 2012. Lag effects in morphodynamic modelling of engineering impacts.

Langston, W., B. Chesman, G. Burt, J. McEvoy, and N. Pope. 2003. Bioaccumulation of metals in the Thames Estuary. Environment Agency. Reading(UK) (8).

Lavery, S., and B. Donovan. 2005. Flood risk management in the Thames Estuary looking ahead 100 years. Philosophical Transactions of the Royal Society of London A: Mathematical. Phys Eng Sci 363(1831):1455-1474.

Lesser, G., J. Roelvink, J. Van Kester, and G. Stelling. 2004. Development and validation of a three-dimensional morphological model. Coast Eng 51(8):883-915.

Loder, T.C., and R.P. Reichard. 1981. The dynamics of conservative mixing in estuaries. Estuaries Coast 4(1):64-69.

Lotze, H.K., H.S. Lenihan, B.J. Bourque, R.H. Bradbury, R.G. Cooke, M.C. Kay, S.M. Kidwell, M.X. Kirby, C.H. Peterson, and J.B. Jackson. 2006. Depletion, degradation, and recovery potential of estuaries and coastal seas. Science 312(5781):1806-1809.

Mikhailov, V., and M. Mikhailova. 2012. Tides and storm surges in the Thames River Estuary. Water Resour 39(4):351-365.

Mikhailova, M. 2011. Long-term variations in river and sea factors responsible for the hydrological regime and morphological structure of the Thames River mouth area. Water Resour 38(4):438-452.

Mitchell, S., L. Akesson, and R. Uncles. 2012. Observations of turbidity in the Thames Estuary, United Kingdom. Water Environ $J$ 26(4):511-520.

Murray, D., P. Dempsey, and P. Lloyd. 2011. Copper in the Thames Estuary in relation to the special protection areas. Hydrobiologia 672(1):39-47. 
Neal, C., R. Skeffington, M. Neal, R. Wyatt, H. Wickham, L. Hill, and N. Hewitt. 2004. Rainfall and runoff water quality of the Pang and Lambourn, tributaries of the River Thames, south-eastern England. Hydrol Earth Syst Sci Discuss 8(4):601-613.

Okubo, A. 1971. Oceanic diffusion diagrams, (Vol. 18. In: Deep sea research and oceanographic abstracts, 789-802: Elsevier.

Paquin, P.R. 2003. Metals in aquatic systems: a review of exposure, bioaccumulation, and toxicity models. SETAC Foundation for.

Pope, N., and W. Langston. 2011. Sources, distribution and temporal variability of trace metals in the Thames Estuary. Hydrobiologia 672(1):49-68.

Power, M., M. Attrill, and R. Thomas. 1999. Heavy metal concentration trends in the Thames Estuary. Water Res 33(7):1672-1680.

Preddy, W. 1954. The mixing and movement of water in the estuary of the Thames. J Mar Biol Assoc UK 33(03):645-662.

Prentice, J.E. 1972. Sedimentation in the inner estuary of the Thames, and its relation to the regional subsidence. Philosop Trans $R$ Soc Lond Ser A Math Phys Sci 272(1221):115-119.

Rossington, K., and J. Spearman. 2009. Past and future evolution in the Thames Estuary. Ocean Dyn 59(5):709-718.

Sanders, R., T. Jickells, and D. Mills. 2001. Nutrients and chlorophyll at two sites in the Thames plume and southern North Sea. J Sea Res 46(1):13-28.

Savenije, H. 2012. Salinity and tides in alluvial estuaries, completely revised 2nd Edn.

Skerratt, J., K. Wild-Allen, F. Rizwi, J. Whitehead, and C. Coughanowr. 2013. Use of a high resolution 3D fully coupled hydrodynamic, sediment and biogeochemical model to understand estuarine nutrient dynamics under various water quality scenarios. Ocean Coast Manag 83:52-66.

Spearman, J.R., A.J. Manning, and R.J. Whitehouse. 2011. The settling dynamics of flocculating mud and sand mixtures: part 2 numerical modelling. Ocean Dyn 61(2-3):351-370.
Stark, J., S. Smolders, P. Meire, and S. Temmerman. 2017. Impact of intertidal area characteristics on estuarine tidal hydrodynamics: a modelling study for the Scheldt Estuary. Estuar Coast Shelf Sci 198:138-155.

Stevenson, C., and N. Betty. 1999. Distribution of copper, nickel and zinc in the Thames Estuary. Mar Pollut Bullet 38(4):328-331.

Thorn, M., and T. Burt. 1978. The silt regime of the Thames Estuary. Hydraulics Research Station.

Thouvenin, B., J.L. Gonzalez, J.F. Chiffoleau, B. Boutier, and P. Le Hir. 2007. Modelling $\mathrm{Pb}$ and $\mathrm{Cd}$ dynamics in the seine estuary. Hydrobiologia 588(1):109-124.

Toffolon, M., and G. Rizzi. 2009. Effects of spatial wind inhomogeneity and turbulence anisotropy on circulation in an elongated basin: a simplified analytical solution. Adv Water Resour 32:1554-1566.

Toffolon, M., G. Vignoli, and M. Tubino. 2006. Relevant parameters and finite amplitude effects in estuarine hydrodynamics. $J$ Geophys Res 111:C10014. https://doi.org/10.1029/2005JC003104.

Toffolon, M. 2013. Ekman circulation and downwelling in narrow lakes. Adv Water Resour 53:76-86.

Vane, C.H., D.J. Beriro, and G.H. Turner. 2015. Rise and fall of mercury $(\mathrm{Hg})$ pollution in sediment cores of the Thames Estuary, London, UK. Earth Environ Sci Trans R Soc Edinb 105(04):285296.

Wang, Z., C. Jeuken, and H. De Vriend. 1999. Tidal asymmetry and residual sediment transport in estuaries: a literature study and application to the Western Scheldt. Tech. report Deltares (WL).

Weston, K., N. Greenwood, L. Fernand, D.J. Pearce, and D.B. Sivyer. 2008. Environmental controls on phytoplankton community composition in the Thames plume, UK. J Sea Res 60(4):246-254.

Wild-Allen, K., J. Skerratt, J. Whitehead, F. Rizwi, and J. Parslow. 2013. Mechanisms driving estuarine water quality: a 3D biogeochemical model for informed management. Estuar Coast Shelf Sci 135:33-45. 


\section{Affiliations}

Valentina Premier $^{1,2}$ (D) . Anderson Abel de Souza Machado ${ }^{2,3,4} \cdot$ Steve Mitchell $^{5} \cdot$ Christiane Zarfl $^{6} \cdot$ Kate Spencer $^{4} \cdot$ Marco Toffolon $^{1}$

Anderson Abel de Souza Machado

machado@igb-berlin.de

Steve Mitchell

steve.mitchell@port.ac.uk

Christiane Zarfl

christiane.zarfl@uni-tuebingen.de

Kate Spencer

k.spencer@qmul.ac.uk

Marco Toffolon

marco.toffolon@unitn.it

1 Department of Civil, Environmental and Mechanical

Engineering, University of Trento, Trento, Italy

2 Leibniz-Institute of Freshwater Ecology and Inland Fisheries,

Berlin, Germany

3 Department of Biology, Chemistry, and Pharmacy,

Freie Universität Berlin, Berlin, Germany

4 School of Geography, Queen Mary University of London, London, UK

5 School of Civil Engineering and Surveying,

University of Portsmouth, Portsmouth, UK

6 Center for Applied Geosciences, Eberhard Karls Universität Tübingen, Tübingen, Germany 